\title{
Do 'objectivist' features of moral discourse and thinking support moral objectivism?
}

\author{
GUNNAR BJÖRNSSON \\ Umeå University, University of Gothenburg
}

\section{Introduction}

Moral objectivism tells us that in (most) paradigm moral disagreements, one party is right and the other wrong, and not just relative to some arbitrary point of view, or because all positive moral claims are false. Arguably, this makes it a particularly important view, with significant methodological, normative and existential repercussions. But it is also a far-reaching claim about actual moral thinking. It implies that different moral judges, each sincerely trying to determine the answer to some paradigm moral question (whether equality is intrinsically valuable, say), are all concerned to get the same non-subjective matter right.

The truth of such a far-reaching claim cannot be determined by introspection or simple observation, but many believe that stable features of moral thinking and moral discourse provide substantial evidential support, roughly as follows:

(1) Normally, people reason and behave 'as if' objectivism were correct.

(2) Objectivism offers a considerably more straightforward (less ad hoc) way of making sense of (1) than do relativism, error theory or noncognitivism.

(3) Consequently, there is considerable prima facie evidence in favor of objectivism.

I will call this argument the straightforward argument for objectivism. ${ }^{1}$

${ }^{1}$ For versions of the argument, see e.g. Brink 1989, ch. 2; Huemer 2005 ch. 2\&3; McNaughton 1988, pp 39-41; Sayre-McCord 2006, p. 42; Shafer-Landau 2003, ch. 2\&3; Streiffer 2003, ch. 1. Since versions of the straightforward argument seem to be the most commonly cited source of support for objectivism in contemporary metaethics, I expect it to be endorsed by a substantial part of the majority of philosophers sympathetic to 
There are various anti-objectivist responses to the straightforward argument. Some argue that metaphysical, epistemic and semantic costs incurred by objectivism outweigh the support provided by (1) and (2). Others dispute (1), arguing that moral discourse and reasoning reveal a relativist or expressivist understanding of the moral domain among a significant number of participants. Others still seek to undermine (2) by defending particular relativist, non-cognitivist or error-theoretic accounts of 'objectivist' features, trying to show that these accounts are straightforward enough, relying primarily or solely on independently plausible assumptions.

In this paper, however, I argue that (2) is untenable because we lack reason to think that there is a straightforward objectivist explanation of 'objectivist' features in the moral domain. The apparent plausibility of premise (2), I will suggest, relies on the assumption that such features have the same basic explanation in the moral domain as they have in paradigmatically objective domains. However, deep and widespread moral disagreement, or more correctly the appearance of such disagreement, strongly indicates that the explanations would have to be different: it is unclear why we would take parties of such moral disagreement to be concerned with a univocal cognitive content. For this reason, objectivists, no less than noncognitivists, relativists and error-theorists, need to provide a detailed special explanation of why we behave 'as if' objectivism were correct. Pending such an explanation, 'objectivist' features provide no evidence for objectivism. I call this the argument from elusive univocality.

Though reminiscent of familiar arguments from disagreement, the argument from elusive univocality is importantly different. The conclusion, being itself compatible with the truth of objectivism, is obviously weaker than the conclusion of many other arguments from disagreement. However, the conclusion that

objectivism. (According to a 2009 survey of almost a thousand professional philosophers (http://philpapers.org/surveys/results.pl), the majority accepts or leans toward 'moral realism'; similar results were obtained for graduate students in philosophy. ('Moral realism' is often understood as implying what I call 'moral objectivism'. There are exceptions, though: see e.g. Sayre-McCord 1991, who takes realism to be compatible with forms of relativism.)) 
'objectivist' features fail to support objectivism does challenge the standard (objectivist) understanding of the metaethical dialectic and seems to leave us without any substantial evidence for objectivism. If nothing else, this gives us reason to take the alternatives even more seriously, to consider other possible reasons for accepting objectivism, and to think more carefully about what special explanations might be available to objectivists. Moreover, although the conclusion falls short of a direct refutation of objectivism, the premises of the argument are also correspondingly weaker and easier to defend. While the argument from elusive univocality assumes that many paradigmatic cases of moral disagreement seem to depend on fundamentally different moral outlooks, it presupposes neither that there is such radical disagreement, nor that objectivism would ultimately be unable to account for it. Because of its weaker premises, I will argue, it avoids standard objectivist strategies for handling arguments from disagreement.

\section{Objectivism as a substantial thesis about paradigmatic moral disagreements}

Since the term 'objectivism' has been used to signify a variety of positions in ethical theory, it will be important to clarify the view at issue. As understood here, objectivism about a concept expressed by a term ' $\mathrm{F}$ ' can be spelled out as the combination of cognitivism, realism and absolutism:

Cognitivism: Thoughts to the effect that some $\mathrm{X}$ is $\mathrm{F}$ have truth- or correctness-conditions. Correspondingly, the concept expressed by ' $F$ ' has satisfaction-conditions, picking out the class of objects of which it is correct to say that they are F.

Realism: There are, or could be, things that are F.

Absolutism: For any two individuals $\mathrm{A}$ and $\mathrm{B}$ and any object $\mathrm{X}$, if $\mathrm{A}$ thinks that $\mathrm{X}$ is $\mathrm{F}$ and $\mathrm{B}$ thinks that $\mathrm{X}$ is $\mathrm{F}$, then A's thought is true or correct (false or incorrect) if and only if B's thought is. Moreover, if A thinks that $\mathrm{X}$ is $\mathrm{F}$ and $\mathrm{B}$ thinks that $\mathrm{X}$ is not $\mathrm{F}$, then if $\mathrm{A}$ 's thought is true or correct, B's thought is false or incorrect. 
So defined, objectivism about moral concepts is rejected by classical noncognitivists, relativist and error-theorists. ${ }^{2}$ At the same time, it is part of a wide variety of metaethical positions: rationalist, idealist, naturalist and non-naturalist. ${ }^{3}$

${ }^{2}$ Non-cognitivists like Ayer (1946) reject cognitivism, relativists like Dreier (1990), Finlay (2009), Harman (Harman and Thomson 1996) and Wong (1984) reject absolutism, and error-theorists like Joyce (2002) and Mackie (1977) reject realism.

${ }^{3}$ Objectivism is part of Kant's transcendental ethics and among contemporary Kantians

${ }^{3}$ Objectivism is part of Kant's transcendental ethics and among contemporary Kantians such as Christine Korsgaard (1996, 2009), naturalistic ('Cornell') realism (Boyd 1988; Brink 1989, 2001), version of what Sharon Street (2006) calls 'rigidifying antirealism', ideal observer or advisor theories (Firth 1952; Hare 1981; Smith 1994), as well as typical non-naturalistic theories (Huemer 2005; Moore 1903; Parfit 2005, 2011; Shafer-Landau 2003). (In contrast to Firth or Smith, Hare insists that moral statements are prescriptive rather than descriptive. But he still thinks that constraints on moral language are such that, absent mistakes of reasoning and ignorance about relevant non-moral matters, every judge would make the same moral judgment.)

Some uses of 'objectivism' rule out ideal observer theories because they make moral facts constitutively dependent on the attitudes of moral judges. For a discussion of the relevance of different notions of objectivity, see e.g. McDowell 1983, 1985. 'Objectivism' is also sometimes used to signify non-naturalist forms of what I call moral absolutism.

Absolutism concerns thoughts and concepts, not language. Suppose that 'wrong' means 'violates norm N', where $\mathrm{N}$ is determined contextually, thus giving talk and thought about wrongness different correctness-conditions in different context. Absolutism might still be true about our concept of moral wrongness if thoughts about what is morally wrong always relate to the same (relatively determinate) moral (rather than aesthetic, legal, etc.) norm. On the other hand, absolutism about moral wrongness is incompatible with the idea that our concept of moral wrongness is itself contextualist in that sense that it relates to different, incompatible standards in different contexts. It is also incompatible with the claim that although everyone's concept of moral wrongness signifies a non-relative property, not everyone's signifies the same non-relative property.

Various forms of absolutism might be trivially satisfied given cognitivism. Suppose, for example, that the concept expressed by the predicate 'immoral' has satisfactionconditions that are relative to appraisers and times. Then absolutism would not hold for $\mathrm{F}=$ immorality, but it would hold for $\mathrm{F}=$ immorality relative to $N N$ at $t$. However, the forms of objectivism that have been at the focus of the debate concern non-relativized kinds 
Two qualifications are needed, however. First, as it stands, objectivism might be acceptable given projectivist, quasi-absolutist, or quasi-realist forms of relativism or non-cognitivism. On such positions, a person's endorsement of the claims by which I have defined cognitivism, absolutism and realism might not express a substantial metaethical view on moral semantics and ontology. Instead, it might just be the projection of a non-relativistic moralistic stance, reflecting the fact that the person holds the moral judgments of any two judges to the same judge-independent standard of correctness, because, say, these judgments have the same conative and practical upshots. ${ }^{4}$ Objectivism, then, should be understood as the combination of cognitivism, absolutism and realism, where the correctnessconditions in question are relevantly non-projective and judge-independent. ${ }^{5}$

A second qualification is needed to rule out excessive amounts of moral indeterminacy, i.e. cases where it is neither true nor false that an action falls under a certain moral concept. If most difficult moral controversies were cases of moral indeterminacy, we would have to abandon the core objectivist idea that objective facts determine correct answers to difficult moral questions. ${ }^{6}$ For example, it should not be enough that moral claims have abstract 'formal' truth-conditions (that an act is immoral when it doesn't give appropriate weight to the interest of those involved, say) if its defining concepts (appropriate weight, interest, being

of judgments that are of interest to people in general: judgments about what we have most reason to do; what we ought to, must, or must not do; or about what contributes to a good life or a just society.

${ }^{4}$ See Blackburn 1993, pp. 166-81; Gibbard 2003, ch. 4 \& 14; MacFarlane 2007.

${ }^{5}$ It has turned out to be surprisingly difficult to distinguish quasi-realism from moral objectivism. For previous discussion, see e.g. (O'Leary-)Hawthorne and Price 1996; Blackburn 1993; Boghossian 1990; Divers and Miller 1994; Dreier 2002, 2004; Dworkin 1996; Gibbard 2003; Harcourt 2005; Lenman 2003; Nagel 1997; Rosen 1998; Sinclair 2006; Stoljar 1993; Wright 1985. However, since I have argued elsewhere that there is a satisfactory way of defining substantial non-projective correctness-conditions, and since the debate about the correctness of objectivism presupposes the intelligibility of non-projective correctness-conditions, I will simply assume that we understand such conditions well enough.

${ }^{6} \mathrm{Cf}$. Dummett 1959 about bivalence as a mark of realism. 
involved) were too indeterminate to yield clear positive or negative verdicts in most paradigm cases of moral disagreement. In what follows, then, I will understand absolutism about a moral concept to include determinacy, the (vague) condition that in most paradigm cases of disagreement about whether something falls under the concept, one party of the disagreement is right. ${ }^{7}$

What should be clear from this characterization, and what is important for the ensuing argument, is that moral objectivism about familiar moral concepts has substantial socio-psychological implications. Consider the set of paradigmatic cases of moral disagreements, involving deontologists and utilitarians, liberals and communitarians, nationalists and internationalists, Rawlsians and libertarians, vegetarians and omnivores, and so forth. Objectivism implies that in most these cases, the disagreeing parties are all concerned with the application of a common concept with non-projective, judge-independent, relatively determinate and satisfiable satisfaction-conditions. Clearly, a claim that stipulates such a highly specific and demanding relation between the concerns of the parties of these disagreements goes well beyond what can be known by a priori conceptual analysis.

The most direct way to argue that this relation holds would be to derive sufficiently determinate correctness-conditions from some properties of moral concepts (e.g. universality, prescriptivity, categoricality), perhaps in conjunction with some universal properties of moral judges. However, such arguments, often inspired by Kant, have failed to convince: the characterization of moral concepts or moral judges needed for such derivation have turned out to be no less controversial than the normative views at stake in paradigmatic moral disagreements. Instead,

\footnotetext{
${ }^{7}$ More precisely: most paradigm cases of disagreement are cases where exactly one party is right (i.e. not cases of true contradictions or indeterminacy).

Brink (1989, p. 202), Shafer-Landau (1994, 2003, pp. 118-20) and Sturgeon (1994, p. 96) argue that objectivism should allow for some amounts of indeterminacy. Moral objectivism, as understood here, allows that moral concepts are somewhat indeterminate, that common sense morality is conceptually confused in various ways and that everyday controversy about, say, justice or immorality are sometimes in need of disambiguation and that the correctness-conditions of moral concept vary somewhat from moral judge to moral judge.
} 
many proponents of the straightforward argument think that objectivism, and in particular its absolutist component, gets this support indirectly, from features that moral discourse and moral thinking share with discourse and thinking in paradigmatically objective domains.

\section{The straightforward argument for objectivism}

These are the bare bones of the straightforward argument for objectivism about some moral concept M:

(1) Normally, and in paradigmatic cases of moral disagreement, people reason and behave 'as if' objectivism were true about $\mathrm{M}$.

(2) Objectivism provides a considerably more straightforward (less ad hoc) way of making sense of (1) than do relativism, error theory or non-cognitivism about $\mathrm{M}$.

(3) Consequently, there is considerable prima facie evidence in favor of objectivism.

Versions of the argument are found throughout the literature (see footnote 1), but are also frequently encountered in conversation with both moral philosophers and students. In this section, however, my concern is to spell out what I take to be the most plausible version of the argument, and to defend it against recent criticism, thus making sure that my own negative argument has the appropriate target.

Start with premise (1). A variety of behaviors exemplify behaving 'as if' objectivism were true. These are behaviors found in discourse and thinking involving paradigmatically objective concepts, but absent in discourse involving concepts that are paradigmatically relative, merely expressive, or lacking referents. Such behaviors include not asking for explication of hidden relative-clauses, directing inquiries primarily towards the objects of judgment rather than towards ourselves as judges, taking the concept to apply in a number of actual cases, taking assessments of the correctness of judgments to hold independently of whose judgment it is, engaging in argument with people who reject claims that we accept, and thinking that our reasons for accepting a claim are reasons to think that someone who rejects it is thereby mistaken. 
Since premise (1) of the argument must be theoretically neutral to provide evidence for objectivism against its rivals, these behaviors must be understood in the right way. In particular, premise (1) cannot in itself presuppose that people believe that objectivism is correct, or even that it seems to be correct. This is simply a central part of what objectivists, relativists, non-cognitivists and errortheorists tend to disagree about: these days, most non-cognitivists and relativists deny that our everyday understanding of moral discourse and moral thinking is mistaken; what is mistaken is the objectivist philosophical interpretation of this understanding. Consider one particularly striking way of behaving 'as if' one took objectivism to be true, namely to explicitly agree with its statements or statements implied by it. Such behavior could be part of the evidence for the first premise, but interpreting it as an expression of belief in non-projectivist absolutism or objectivism is a further step, and one that is supposed to be supported by the straightforward argument.

A natural objection to premise (1) is that many people not only fail to explicitly endorse the claims that define moral objectivism, but also seem to explicitly reject them, saying that a certain moral claim is 'true for us but not for them', or that some moral claims are neither true nor false. ${ }^{8}$ However, I will assume here that objectivists can discount such (apparent) rejections of absolutism, for either of two reasons. First, many such statements can be seen as theoretically innocent sociological, methodological or dialectical claims to the effect that people have very different moral views, or that there is no clear agreed-upon set of data

${ }^{8}$ For example, Gilbert Harman (1998, p. 5) reports that a large portion-perhaps a majority - of Princeton undergraduates has relativistic reactions to radical disagreements; I have had similar experiences with both undergraduates and laymen at public lectures. Recently there have also been some empirical investigations revealing considerable variation in apparently objectivist intuitions (Goodwin and Darley 2008), and some empirical evidence suggesting forms of cultural relativism (Sarkissian et al 2011). Ken Yasenchuk (1997) argues that diversity of moral phenomenology undermines Brink's claim that ordinary moral experience puts the burden of proof on the antirealist (cf. Loeb 2007, pp. 472-4; Nichols 2004). Another possible reaction to differences in intuitions about radical disagreements is to argue that judgments made by different people need different metaethical accounts; for a defense and development of this idea, see Francén 2007. 
and no clear and agreed-upon method that will indicate a specific solution to moral disputes. Second, the fact that different people endorse different metaethical positions is not obviously relevant for the correctness of these positions. Regardless of their metaethical proclivities, it might be argued, most peopleincluding the parties of paradigmatic moral disagreement-behave 'as if' they accepted objectivism when they are engaged in moral thinking and moral debate rather than commenting upon it. Arguably, the primary task of a metaethical theory is to account for this engaged behavior, rather than for what is in effect lay people's theoretical interpretations of it. ${ }^{9}$ These reasons might be disputed, but I take them to be strong enough to grant the first premise for the sake of argument. A careful discussion of the empirical data on people's objectivist tendencies would take us too far, as my primary goal is to show how the second premise is undermined by other considerations.

The requirement of theoretical neutrality also has important consequences for how we should understand the way in which 'objectivist' features can support objectivism. In particular, it makes problematic the claim that objectivism is uniquely placed in offering a 'vindicating' or 'charitable' interpretation of our practices. It is of course true that an error-theory would fail to vindicate our moral judgments, and this might give us some (defeasible) reason to interpret their correctness-conditions as metaphysically less demanding than what error-theorists typically propose. More contentiously, it might give us some (defeasible) reason to think that the world contains what is needed to make our judgments true once these judgments have been given an otherwise plausible interpretation, at least in the absence of independent reason to think that our judgments are unreliable. But unless it is already assumed that the content of these judgments and our attributions of moral agreement and disagreement are best understood along absolutist lines, it is not at all clear why objectivism would do a better job vindicating our moral thinking and moral discourse than would expressivism or relativism. So, since absolutism is itself part of what is supposed to be supported with reference to

\footnotetext{
${ }^{9}$ Compare the treatment of apparently relativistic discourse in Timmons 1999 , pp. $150-52$.
} 
'objectivist' features of morality, at least its support would have to be grounded in something other than a principle of vindication. ${ }^{10}$

There is another way of understanding how 'objectivist' features are supposed to support objectivism, however, a way which does not blatantly beg the question in favor of absolutism and objectivism. It depends on a different and more general explanatory virtue than vindication: that of not relying on principles or mechanisms that lack sufficient independent motivation but are invoked ad hoc to support the theory in question. The second premise of the straightforward argument thus claims that objectivism offers a superior explanation of 'objectivist' features in just this regard: an explanation is 'straightforward' in the relevant sense if it invokes no ad hoc principles or mechanisms.

Insofar as objectivists do not just take something like the second premise as obvious, it is usually supported by detailed criticism of various non-cognitivist or relativist efforts to explain or explain away objectivist behavior. It is a striking fact, however, that objectivists have themselves offered very little if any explanatory detail, thus seemingly leaving us without basis for the relevant comparison. Here is Don Loeb, protesting that something like the second premise cannot just be taken for granted:

But if we are to accept the objectivist's explanation as best, we need more than the mere claim that we experience morality as objective because it is objective. We need to know how its being objective can explain our having the experiences we do. Or at least we need some good reason for thinking that its being objective would explain why our experience turns out as it does. But such a reason has not been given in the context of this argument, and we cannot simply assume that one is available (Loeb 2007, p. 476).

10 Objectivism might also fail to fully vindicate our practice by implying that we irrationally take parties of moral disagreements to be concerned with the same issue, or have an irrational confidence in our own moral judgments. The discussion in the following sections provides some support for the first of these worries. 
I agree with Loeb that we need reason to accept the second premise, and agree that none has been stated. ${ }^{11}$ Moreover, I will later argue that when we start looking at the explanatory details, the support for the second premise crumbles. But I do not think that objectivists have merely begged the question. Prior to considering explanatory details, there has indeed been good reason to think that objectivism can explain 'objectivist' features relying on fewer unsupported assumptions than the non-cognitivist, relativist or error-theoretic alternatives. Moreover, I think that objectivists who have offered the straightforward argument have more or less consciously had this reason in mind.

The reason is the following: Fittingly, people display objectivist behavior in relation to concepts of paradigmatically objective matters, but not in relation to concepts of paradigmatically non-objective matters (such as concepts of what is tasty or to the right). Moreover, it can reasonably be assumed that people possess fairly reliable mechanisms that have adapted their behavior in such ways. This reliability has its limits, of course. Relativistic physics seems to imply that we have been massively mistaken about the absolutist character of ordinary physical properties such as weight and length. Moreover, and even given fairly liberal ontological strictures and charitable interpretations, people have mistakenly made extensive use of concepts that lack referents - the concept of a witch and scientific concepts like phlogiston and luminiferous ether are stock examples. But these mistakes are, in a way, out of the ordinary. Arguably, the sort of mistakes involved in taking there to be witches or phlogiston are relatively few and far between relative to the vastness of our overall conceptual repertory, and the relativity of physics is highly esoteric: restricted to everyday frames of reference and ordinary everyday judgments attributing weight or length using established scales,

11 This is not to say that objectivists have done no explanatory work of relevance for the straightforward argument. In particular, their efforts to explain how absolutism might be compatible with deep moral disagreement do suggest ways in which objectivists might want to explain 'objectivist' behavior. Such suggestions will be discussed in the sections that follow. Moreover, various arguments have been given for cognitivism and against noncognitivism, invoking difficulties for non-cognitivists to account for moral reasoning, for explanations of natural events in moral terms, and for the seeming possibility of amoralists. Our concern here, however, is primarily with absolutism. 
absolutism still holds. Generally speaking, then, it is reasonable to expect our displays of objectivist behavior to track areas of discourse that concern objective matters of fact, or matters whose relativity is esoteric. Taking only these considerations into account, then, and judging the matter prior to considering special reasons to be suspicious about their application to the moral case, it does seem likely that objectivist behavior in moral thinking and discourse is explained by moral objectivism. ${ }^{12}$

This is not yet to say how objectivism explains objectivist behavior: it is just to say that the case of moral judgments follows the general pattern. But pending convincing evidence to the contrary, it seems reasonable to assume that whatever accounts for our behavior in paradigmatic cases of objectivist discourse is at work here too. Moreover, whatever the account would be when spelled out, it is straightforward in the sense that it invokes no ad hoc and otherwise unsupported explanatory principles to make sense of what seems to be a familiar kind of phenomenon. ${ }^{13}$

${ }^{12}$ Sharon Street (2006) argues at length that 'realist' theories of value cannot be reconciled with plausible evolutionary or naturalistic accounts of our moral judgments. Even if Street were right, this would not affect the present argument, as 'objectivism' in the present sense can take the form of what Street calls 'rigidifying antirealism', thus falling outside the scope of her argument.

${ }^{13}$ The second premise can be expanded by spelling out the relevant way in which objectivism is supposed to make sense of the objectivist behavior. For example, it could be divided into the following two premises:

(2a) The most straightforward explanation of why we behave 'as if' objectivism were true is that we do accept objectivism.

(2b) The most straightforward explanation of why we accept objectivism is that it is correct.

An alternative explanation of (1) would take it that our behavior has been adapted (biologically, culturally, through the ordinary process of acquiring the relevant language) to the fact that objectivism is correct even though we have no corresponding belief that it is correct. Though these are significantly different ways of spelling out (2), they will make little difference to our discussion. 
Contrast this with what is needed for the competing accounts. In explaining our objectivist behavior, non-cognitivists develop special explanations of what we do when we attribute truth, falsehood or correctness to moral judgments (Blackburn 1998, ch. 3, 9; Timmons 1999, ch. 4), of what it is to think that an action's immorality, say, is independent of our moral disapproval of it (Blackburn 1993, pp. 166-81), of why we take moral disagreements to be more than mere disagreements about taste - a paradigmatically non-objective matter (Blackburn 1998; Gibbard 1990, 2003; Stevenson 1937, cf. Schroeder 2008b) —and, not least, of why moral predicates and deontic operators behave syntactically and logically just like ordinary descriptive predicates or modal operators. Judging from state-ofthe-art attempts, in particular those of Allan Gibbard and more recently Mark Schroeder (2008a), any successful non-cognitivist explanation is bound to be far from obvious, very complex, and building on a variety of assumptions about our practical psychology that likely go far beyond what explains objectivist behavior in paradigmatically objectivist discourse.

Unlike non-cognitivists, relativists might have a straightforward explanation of why moral predicates behave like ordinary descriptive predicates-they are ordinary descriptive predicates. But they need explanations of behaviors normally found only in absolutist discourse, in particular behaviors relating to the sense that we can agree or disagree morally with people that the relativist thinks employ concepts with different satisfaction-conditions. Relativist proposals to understand such disagreement in terms of the practical role of normative concepts or semantic insensitivity (see e.g. Björnsson and Finlay 2010; Copp 2000, pp. 120-4; Ryan 2003; Wong 1984, p. 73) seem to appeal to other mechanisms than those operative in paradigmatically absolutist domains of discourse, and even relativists agree that considerable detail and argument are needed to make these explanations fully convincing.

Error-theorists, finally, need to explain why we pervasively fall into the error of attributing objective moral properties when nothing has such properties. Here, error-theorist appeals to mechanisms of projection and objectification, or to an alleged evolutionary benefit of mistakenly postulating objective values (Joyce 2002, ch. 6; Mackie 1977, pp. 42-6) surely go far beyond what typically explains objectivist behavior. 
Overall, then, 'objectivist' features of moral discourse and thinking seem to support objectivism because objectivism promises to explain these features in whatever way they are typically explained elsewhere, thus avoiding postulation of ad hoc mechanisms. Without indicating any particular account of non-relative correctness-conditions for moral judgments, or any particular analysis of moral facts, the straightforward argument thus seems to give us reason to think some such account would be right. Moreover, if objectivists have understood the straightforward argument in this way, it would explain why they have done little themselves to explain these features, focusing instead on identifying problems with rival explanations and on answering specific challenges raised by critics. But while reliance on the straightforward argument makes good sense given this information, I will now argue that objectivists will have to find some other source of support for their theory.

\section{Undermining the argument: Preview}

The straightforward argument rests on one restricted piece of information: that people display 'objectivist' behavior when engaged in moral discourse and moral thinking. Further considerations might well undermine or outweigh this evidence, and standard criticism of objectivism holds that it is (a) incapable of accounting for the connection between moral judgments and motivation to act, (b) has no plausible way to accommodate widespread deep moral disagreement, and (c) presupposes the existence of facts of a sort that we have reason to think do not exist.

Objectivists have tried at length to reply to these objections, and some replies might be quite convincing (see e.g. Boyd 1988; Brink 1989; Huemer 2005; ShaferLandau 2003; 2006). What we will see, however, is that a very modest argument from disagreement is enough to undermine the second premise of the argument. Even granted that we should expect widespread deep disagreement given objectivism, the appearance of such disagreement poses a dilemma for the objectivist: Either 'objectivist' behavior in moral discourse would have to be explained differently than objectivist behavior in relation to paradigmatically objective judgments, or the mechanisms in question are too blunt to reliably track whether objectivism holds for moral judgments. Without the assumption that 
objectivist behavior is explained in the same way in both domains and explained by mechanisms that reliably track whether objectivism holds or not, the rationale behind the second premise of the straightforward argument is lost. To show that they have an explanation of superior plausibility to the explanations provided by relativists, non-cognitivists and error-theorists, or even to show that they have one with any plausibility, objectivists need to get their hands dirty and provide explanatory detail.

To make these claims plausible, I will outline the sorts of explanation of objectivist behavior that seems operative in paradigmatically objective domains. In particular, I will discuss how people come to take each other to be concerned with the same or different properties, or with the same or different satisfactionconditions in different domains. I will consider two broad kinds of mechanisms. The first is a sensitivity to fundamental criteria for concept application, most clearly exemplified in abstract sciences like logic, geometry and mathematics. The other is a sensitivity to what aspect of reality people are interacting with and keeping track of using their concepts, most clearly exemplified in our dealing with terms signifying physical objects, kinds, stuffs, properties and relations. These mechanisms correspond to, respectively, internalist and externalist ideas in philosophy of language and psychology of what determines the truth or correctness-conditions of thoughts or utterances and the satisfaction-conditions or referents of concepts and terms.

The claim will be that apparently deep moral disagreement makes it unclear how these mechanisms could explain objectivist behavior with regard to core moral concepts like obligation, right, or immorality. If correct, this undermines the claim that objectivism provides a straightforward explanation of these behaviors. Much of what follows will serve merely as a reminder of considerations adduced in typical arguments from disagreement; what is new is how these considerations are employed to undermine the straightforward argument for objectivism rather than to undermine objectivism. This weaker conclusion, we will see, is much easier to defend, but it leaves objectivism without the support most commonly adduced in its favor. 


\section{The elusiveness of common satisfaction-conditions for moral concepts}

To see whether the rationale for the second premise of the straightforward argument stands up to closer scrutiny, we need to identify the mechanisms by which a kind of judgment come to be treated as objective, relative, or concerned with a fictitious matter, and we need to consider whether these mechanisms are reliable.

In doing so, our focus should not be on interactions with particular judgments, but on kinds of judgment, such as judgments of moral wrongness, judgments of taste, judgments about whether something is to the left or right, etc. Moreover, our primary interest is in mechanisms responsible for general stable dispositions to engage or not in 'objectivist' behavior in relation to this kind, not on mechanisms responsible for 'objectivist' behavior on particular occasions. For example, it might well be that we start with the assumption that people who use the same subject or predicate expression or engage in dialogue using anaphoric expression in a certain way express concepts with the same satisfaction-conditions. It might also be that we initially just adopt the sort of behavior displayed by others in relation to the relevant kind of judgment, adopting 'objectivist' behavior in domains where others display such behavior. Such mechanisms might explain 'objectivist' behavior on early encounters with judgments of the relevant kind. But unless there are sensitive enough mechanisms that lead us to abandon default assumptions and depart from pre-existing behavior in the face of non-objectivist discourse, stable general behavioral dispositions will not reliably track whether objectivism holds or not. What we are looking for, then, are mechanisms that seem sensitive, over the long run, to whether concepts involved in the judgments in question have non-relative satisfaction-conditions that are uniform and precise enough to yield determinate extensions in cases that we are concerned with.

The best-known view of the satisfaction-conditions of concepts is what we might call the criterial view. On this view, $\mathrm{S}$ is the satisfaction-condition of A's concept $\mathrm{C}$ if and only if $\mathrm{A}$ takes $\mathrm{C}$ to apply insofar as condition $\mathrm{S}$ is satisfied. Classical versions of the criterial view restrict this to fundamental criteria. These are criteria that we take to provide overriding grounds for accepting a judgment; 
other considerations are taken to provide grounds only to the extent that they indicate that the fundamental criteria for the concepts involved are satisfied. ${ }^{14}$

The criterial view of satisfaction-conditions is hardly uncontroversial. ${ }^{15}$ What is clear, however, is that sensitivity to fundamental criteria of concept application often does affect whether we take two people to be talking about the same thing, and thus whether we engage in 'objectivist' or more specifically 'absolutist' behavior; whether we engage in argument, ask for clarification of implicit relativeclauses ('to the right seen from your direction?'), take each other to agree or disagree, and so forth. The abstract sciences might provide the clearest examples. When axioms or rules are known to yield diverging results in the domain that concern us, it is natural to relativize claims to different formal systems, or different logics: absolutist behavior is abandoned. ${ }^{16}$ Sensitivity to something like fundamental criteria is also clearly at play in paradigmatic examples of conceptual truths. For example, unless someone takes the fact that John is married as conclusive evidence that he is not a bachelor, we will think the term 'bachelor' is used in an extended or idiosyncratic sense. Of course, as the history of philosophical analysis shows, it is typically very difficult to identify both necessary and sufficient fundamental criteria for complex concepts that have not been introduced by rigorous definition. But failure to articulate such criteria does not itself mean that they are absent. Where there is interpersonal and intertemporal coincidence in judgment or in the use of a certain term across a variety of cases, we might have reason to think that people have similar enough criteria of application, at least for that range of cases (cf. Lewis 1997, p. 340).

If we assume that this is right and also assume that sameness of satisfactionconditions consists in agreement in fundamental criteria, this gives us a reasonably

\footnotetext{
${ }^{14}$ For a recent defense of a version of the criterial view, see Braddon-Mitchell 2004, Chalmers and Jackson 2001, Jackson 1998; for a defense of its application to moral concepts, see Jackson and Pettit 1995 and Jackson 1998, ch. 5-6.

${ }^{15}$ See e.g. Millikan 2000, 2010.

${ }^{16}$ This is not a uniform phenomenon: some argue that, and behave as if, there is one correct logic, where this goes beyond the claim that there is one best interpretation of natural language logical constants (for discussion, see Eklund forthcoming). What is clear, however, is that absolutist behavior tends to be restricted under such circumstances.
} 
clear idea of how absolutism can explain 'absolutist' behavior in certain domains. The problem is that it is hard to see how this explanation can be reconciled with the claim that 'absolutist' behavior has the same explanation in the moral domain.

One immediate difficulty in applying the criterial view and corresponding explanations of objectivist behavior to the case of moral judgments is that there seems to be little general agreement in determinate criteria for applying various moral concepts. This is not to say that everything is vague and unprincipled. For example, we seem to accept as a fundamental criterion for taking some behavior to be morally wrong, right or mandatory that it is within the control of an agent in some sense. Also, most of us take as rather fundamental the presumption that lying, behaving disrespectfully, breaking promises and harming or killing the innocent is wrong. However, there seems to be great variation when we look at what form of control we require for moral responsibility, what considerations we take to cancel normative presumptions, whom we take to be protected by such presumptions, or what we take to constitute disrespect, innocence, 'white' lies, and so forth. There is also considerable variation in judgments about how much help we owe to others, and to what others we owe any help. In sum, whatever criteria we accept seem to vary from person to person, from culture to culture, and be rather flexible, situational, and vague. This, of course, is one familiar ground for accepting relativism, and it seems hard to deny that it provides prima facie evidence against absolutism (and hence objectivism) given the criterial view.

Absolutists claim to be able to accommodate such variation, trying to show that it is what could be expected if absolutism were true (e.g. Brink 1989, pp. 197210). ${ }^{17}$ For example, since moral judgments are closely tied to moral emotions and action, we can expect them to be subject to a variety of well-known emotional and decision-theoretic biases (Huemer 2005, ch. 6). Moreover, absolutists can insist that the fundamental criteria that we all do accept are highly abstract, thus leaving a lot of room for non-moral mistakes, biases and contextual factors to affect our judgments. One common suggestion appeals to a process of reflective equilibrium through which definite enough criteria for application might be discovered (Brink

${ }^{17}$ Brink's excellent discussion of moral disagreement applies in spite of his rejection of the criterial view. 
2001; Merli 2002, p. 223; Schroeter and Schroeter 2009, pp. 11-15; Jackson 1998, pp. 131-135). The rules governing this process could themselves be taken to constitute higher-order criteria which could say, for example, that an act is immoral insofar as it would violate the socially enforced norms that are or would be arrived at through a process of reflective equilibrium.

The possibility of abstract or higher order criteria suggests that absolutism is compatible with and perhaps even predicts widespread and deep disagreement. However, our concern here is whether 'objectivist' and more specifically 'absolutist' behavior in moral thought and discourse could be explained in terms of a sensitivity to whether fundamental criteria of concept application coincide. This seems highly doubtful. Without assuming absolutism, there is little evidence that people would arrive at the same fundamental criteria when going through a process of reflective equilibrium. To make it plausible that they would, the process of reflective equilibrium must be given a more definite content than anyone has mustered so far without invoking highly contestable second-order criteria. ${ }^{18}$ Given this, and given that deep and widespread disagreement about the extension of moral terms seems to provide strong prima facie evidence that fundamental criteria of application vary, it seems unlikely that 'objectivist' behavior in the moral domain is governed by a reliable sensitivity to coinciding fundamental criteria. The criterial view of satisfaction-conditions thus leaves us without reason to think that objectivism provides the more straightforward explanation of this behavior. ${ }^{19}$

${ }^{18}$ Objectivists often blame the lack of agreement on fundamental issues in normative ethics on the fact that normative inquiry without religious or political dogmas is a young discipline (Brink 1989, pp. 205-6; Lear 1983, p. 60; Parfit 1984, pp. 453-4; Shafer-Landau 2003, p. 219; Smith 1994, p. 188). But although the youth of the discipline might weaken the negative induction from past failure of rational convergence to future failures, it provides no positive reason to think that there will be such convergence. David Merli (2002, p. 224) thinks that we need to look at specific work in normative theory to see reasons to expect convergence. Even if such specific details were forthcoming, however, they would give no force to the straightforward argument.

${ }^{19}$ Similar worries concern related views of reference. For example, defenses of realism sometimes appeal to what we would end up with at the end of inquiry, or to moral kindskinds acknowledged by a mature moral science (Copp 2000, pp. 124-34; Sayre-McCord 
Of course, the criterial view has a well-known alternative, which takes the referent of a concept to be whatever stands in the appropriate causal relation to the concept. ${ }^{20}$ The best-known application of a causal account of reference to moral concepts comes from Richard Boyd. According to Boyd, the referent of a term is the property that our use of the term has tracked-accumulated information about - in ways that have systematically reinforced the continued employment of the term. In the case of 'good', as used in moral contexts, this is the property of being conducive to human flourishing. Although people have very different ideas about the nature of what is morally good and about what instantiates the property, and seem to accept different fundamental criteria for assigning moral value, it is, generally speaking, success in tracking this property that has reinforced the use of the term (Boyd 1998; 2003a). Both Boyd's causal-regulatory view of reference and his particular application of it to moral terms have faced serious criticism, but since it is at least an open question whether this criticism can be dealt with, I need to explain why the causal view will not help the straightforward argument. ${ }^{21}$

The issue, remember, is whether stable general dispositions to 'objectivist' and more specifically 'absolutist' behavior in relation to moral judgments could be

1997). However, unless the relevant constraints of moral inquiry are specified, there is little reason to think that such descriptions pick out anything remotely determinate. Similarly, Philip Pettit $(1998,1999)$ formulates the criterial view to allow for considerable opacity and dynamics and thereby convergence through conceptual discovery, but gives no straightforward reason to think that there will be such convergence. And there seem to be contrary evidence: the debate concerning various kinds of ideal observer or advisor models shows that as soon as details about these ideal observers are filled in to yield determinate implications, controversy ensues. For related difficulties, see Holland 2001, Horgan \& Timmons 1996, 2009.

${ }^{20}$ Many moves along these lines were inspired by Hilary Putnam's (1975) paper 'The Meaning of "Meaning"'. For a particularly thorough development of this idea, see Millikan 2000.

${ }^{21}$ For example, Gampel 1996 argues, in effect, that our criteria for concept application are in conflict with the causal-regulatory account. It is also an open question whether 'teleosemantic' views of reference of the sort developed by Boyd and Millikan are adequate for any concepts. See e.g. Fodor 1990, 1996, Papineau 1998 and Price 1998. 
explained in terms of a reliable sensitivity to whether satisfaction-conditions for moral concepts are uniform across speakers. The causal-regulatory account of reference offers hope because there are paradigmatically objective domains where attributions of sameness or difference in content do not seem to rely on evidence of sameness or difference in the attributees' fundamental criteria of application. Instead, attributions seem to be sensitive to what attributees' use of the concepts is in fact tracking when it leads to successful predications and successful interaction with aspects of the environment (be it a person like Mahatma Gandhi, stuff like water, or properties like having a certain length or being a friend). The suggestion, then, would be that whether we have stable general dispositions to display 'objectivist' behavior relative to a certain kind of judgment depends on whether we take the concepts involved to be tracking the same aspect of reality. The question is whether this might be true for moral concepts in a way that underpins the claim that objectivism offers a more straightforward explanation of such behavior.

The best-known problem for causal-regulatory views of moral concepts comes from Terence Horgan and Mark Timmons' Moral Twin Earth arguments (1991; 1992a; 1992b; 2000). In these arguments, we are asked to imagine a planet much like ours, Moral Twin Earth, with a community whose term 'good', say, is used in much the same way as English 'good'. However, though typical applications of the terms overlap significantly, successful uses of Twin-'good' track a slightly different property from uses of our term. Confronted with this scenario, most people seem to agree that we nevertheless could have a substantial disagreement with people in that community about what is morally good. This suggests that intuitions about whether we are concerned with the same issueintuitions driving 'absolutist' behaviors-are insensitive to whether the concepts involved track the same properties in the way required by a causal-regulatory account.

There are various ways in which defenders of the causal-regulatory account might want to reply to this. One is to deny that our intuitions about these sorts of highly abstract cases are reliable, and to insist that if we understood in concrete detail what was involved in 'good' on Twin Earth's tracking a different property 
than 'good' on earth, we would accept that the two terms have different referents. ${ }^{22}$ This would be especially plausible if our remaining intuitions of disagreement could be explained by the reasonableness of (a) translating Twin-'good' into English 'good' (because the two words have largely overlapping extensions and share practical role), and (b) understanding differences in application of Twin'good' and 'good' as nevertheless involving a kind of disagreement, namely disagreement about what to promote (Copp 2000, pp. 120-124). Even if well motivated, however, these replies would undermine the straightforward argument by acknowledging ways in which 'absolutist' intuitions and behavior are explained with reference to sameness in practical role rather than sameness in satisfactionconditions, much in the way expressivists and relativists have suggested. ${ }^{23}$

Apart from the problems raised by Moral Twin Earth arguments, there are reasons to doubt that a general sensitivity to sameness and difference in what is tracked by moral concepts could straightforwardly explain 'absolutist' behavior in relation to actual moral judges. Consider what reinforces the use of predicates. Roughly, the employment of ordinary empirical concepts and vocabulary is reinforced when it yields successful prediction, manipulation and interaction with others who share our concepts and vocabulary. Such reinforcement is possible because referents have reasonably stable properties and can be re-identified in various ways, letting us accumulate and deploy information about them. Similarly, ways of employing moral concepts seem to be reinforced when they yield judgments and actions that accord with one's other moral judgments, as well as with those of other judges. Again, reliable reinforcement is possible insofar as the

${ }^{22}$ As David Merli (2008) notes, expressivists and cognitivists alike seem to have trouble accounting for intuitions about Moral Twin Earth scenarios, making appeal to these intuitions problematic.

23 For related reasons, it does not help objectivists to say, with Wedgwood (2001, pp. 27 29), that 'absolutist' behavior is based on the fact that the judgments of the disagreeing parties have the same consequences for practical reasoning, in particular for what preferences and attitudes we are committed to have. That account endorses an explanation that seems equally open to relativists or expressivists. (Cf. Folke Tersman's (2006, ch 5) suggestion that radical moral disagreement shows that absolutism is false and that this undermines one important reason to accept cognitivism.) 
pattern of "surrounding" judgments is reasonably coherent and stable. A problem for the absolutist appeal to the causal-regulatory view is this: It is part of our (enlightened) common sense understanding of moral psychology that people form groups with different stable and coherent patterns of judgments. Consequently, what saliently reinforces our moral concepts, generally speaking, would seem to be coordination with a relatively restricted set of moral views, and with different sets for different judges. Given the causal-regulatory view of reference determination, it is thus not clear why we would treat moral judges in general as being concerned with one and the same property.

Again, this does not imply that absolutism or objectivism is false, or even that it is incompatible with a causal-regulatory view of reference determination. It just means that objectivists need to provide an explanation of how people come to display absolutist behaviors in light of variations of this sort, and that this explanation needs to be compared with competing accounts. Before such a comparison, 'objectivist' behavior provides no evidence for objectivism.

The appearance of deep and widespread moral disagreement, I have argued, makes it unclear how objectivism would explain 'objectivist' and in particular 'absolutist' behavior on either criterial and causal-regulatory views of reference. Neither of the two mechanisms that most obviously seem to be responsible for whether we take two people to have the same thing or property in mind in paradigmatically absolutist domains seems to be at work in this case. This undermines the straightforward argument.

Call this version of the argument from disagreement 'the argument from elusive univocality'. In what follows, I will consider four possible replies to this argument, most of which are familiar from objectivist or absolutist attempts to deal with standard arguments from disagreement. The first suggests that although we take there to be deep differences in moral views, our absolutist understanding of morality is formed primarily in reasonably coherent moral environments. The second points to the existence of deep disagreements in other domains, raising the question of why the evidence for moral objectivity should be especially problematic. The third argues that non-naturalism makes the problem much less threatening since most disagreements concern naturalistic characterizations of moral properties. The final reply suggests that sameness of satisfaction-conditions 
is not so much something that we discover as something that we create by committing to refer to the same properties as others who use moral language. We shall see that neither reply is successful in saving the straightforward argument.

\section{First reply: Moral uniformity when dispositions are shaped}

A straightforward explanation of 'absolutist' behavior might seem implausible given apparently deep and widespread moral disagreement. But it could be that we come to think that there is such disagreement only after our patterns of interpretation and engagement in moral discourse and thinking have already been settled. If so, typical signs of coinciding satisfaction-conditions might straightforwardly shape our 'absolutist' dispositions, which might then become relatively immune to signs of divergent tracking and criteria of application. If this developmental story were correct and if absolutism were true, it might seem that absolutism could straightforwardly explain our absolutist behavior. ${ }^{24}$

There are two major problems with this reply, however, even granting the dubious claim that we encounter significant signs of divergence only once we have formed an absolutist understanding of moral discourse. The first is that the reply calls for a special explanation of why we would be immune to signs of divergent criteria when such signs do undermine 'absolutist' behavior in other areas of discourse. The second is that this special developmental explanation appeals to a mechanism that is too insensitive to signs of divergence to reliably track whether absolutism holds (as witnessed by the fact that relativists such as Wong (1984, p. 79) and Finlay (2008, pp. 356-7) have appealed to the very some mechanisms). Each problem is enough to undermine the first reply.

\section{Second reply: Disagreement in other domains}

A standard reply to arguments from disagreement and relativity is that apparently intractable disagreements occur not only in ethics, but also in paradigmatically objective domains (see e.g. Huemer 2005, ch 6). Experts disagree about historical

${ }^{24}$ I have not seen this reply in print, but enough people have made it in conversation to merit inclusion. 
events and their causes, the effects of economic policy, and, as Russ Shafer-Landau (2006, pp. 218-224) has recently reminded us, about core philosophical issues such as the existence of free will. ${ }^{26}$ But while comparisons like these might undermine epistemological and metaphysical skepticism based on moral disagreement, ${ }^{27}$ they do not seem to undermine the argument from elusive univocality. To do so, they would have to give us reason to think that 'objectivist' behavior reliably tracks the truth of objectivism even under the sort of deep disagreement that raise worries about univocality. To this end, the objects of comparison - disagreements about the application of certain non-moral concepts-would have to satisfy two pairs of conditions. The first pair is needed to make it plausible that these are disagreements where the 'objectivist' behavior tracks the objectivity of the issue:

Objectivist Behavior: People involved in the disagreements display consistent 'objectivist' behavior with respect to the relevant concepts (to at least the same extent as we do with respect to moral concepts).

Objective Status: Objectivism about the non-moral concepts in question is not seriously contested.

The second pair of conditions is needed to make plausible that 'objectivist' behavior in these cases is explained by other mechanisms than sensitivities to sameness of fundamental criteria of application or sameness of causal regulation, sensitivities that we have already argued are not at work in the moral case:

Extensional Disagreement: The disagreement concerns the extension of the concept in central cases, i.e. in cases that we care about in our normal use of the concept. It does not merely concern the nature of the referent.

Fundamental Disagreement: Disagreement about the extension of the concept in central cases seems to depend on disagreement about the

${ }^{26}$ For a discussion of other 'companions in guilt' arguments for moral objectivism, see Lillehammer 2007.

${ }^{27}$ See footnote 18 . 
nature of the referent, or differences in the parties' most fundamental conceptions of the referent.

Without Extensional Disagreement, sensitivity to causal-regulatory relations might explain objectivist behavior; without Fundamental Disagreement, absolutist behavior might be explained by sensitivity to sameness in fundamental criteria of application.

Common satisfaction-conditions for moral concepts are elusive because many disagreements about immorality, obligation, and intrinsic value seem to satisfy Extensional and Fundamental Disagreement. The problem with the appeal to disagreement outside morality is that intractable disagreements that clearly satisfy Objectivist Behavior and Objective Status seem different. First consider disagreements about whether Lee Harvey Oswald killed John F. Kennedy, or about the long-term effects on GDP of certain kinds of economic stimuli during a depression (Huemer 2005, pp. 134-7). Here parties of the disagreements still seem to share fundamental conceptions of the matters at hand: the identity of Oswald or Kennedy or the notion of killing is not at stake, nor the notion of GDP. The sources of disagreement are found elsewhere and concern the reliability of various historical sources, the psychological and political plausibility of certain conspiracies, the plausibility of certain economic models and mechanisms of economic growth, or depend on access to different data sets. ${ }^{28}$ Similarly for some well-worn philosophical controversies. For example, some disagreements about God's existence seem to concern the extension of a univocal concept of God, as the parties have taken care to identify the sort of deity their arguments concern by making explicit and discussing its essential properties in some detail. However, exactly because of this, these disagreements do not seem to be based on disagreements about the nature of God, but rather on disagreements about rational

${ }^{28}$ An objectivist appeal to disagreements about the interpretation of quantum mechanics needs to make it plausible that people involved in that debate (a) seem to be widely disagreeing about both extension and fundamental criteria for the application of certain concepts and (b) display full objectivist behavior in relation to these concepts. I know too little about the interpretation of quantum mechanics to rule this out with confidence, but strongly suspect that one condition will tend to undermine the other. 
reasoning and evidence in general. Likewise, the clearest disagreements about the existence of universals or abstract objects do not seem to implicate their nature, but seem to stem from methodological disagreements - about the need to postulate such objects for various theoretical purposes, say.

Other deep disagreements outside ethics, in particular disagreements in philosophy, do seem to be based on disagreements about the nature of their subject matters. But they also seem highly contentious as examples of objectivist discourse, failing to satisfy Objective Status and, to some extent, Objectivist Behavior. As an illustration, consider the debate about whether free will and moral responsibility are compatible with determinism. It certainly seems to raise questions about the nature of free will and moral responsibility, but it is also one in which the univocality of 'free will' or 'moral responsibility' is very much in question. Substantial parts of the debate is concerned with distinguishing different varieties of free will or responsibility and debating their importance, rather than with merely arguing about whether we have free will (witness the subtitle of Daniel Dennett's (1984) Elbow Room: The Varieties of Free Will Worth Wanting). Since objectivist behavior is highly circumscribed among at least some participants in this debate, this particular example does not help the objectivist's straightforward argument. Nor does it help that some participants take the core issue to be what qualities people's wills need to have in order for it to be normatively appropriate to hold them responsible, making this another example of fundamental normative disagreement (Wallace 1994). To make matters even worse, there are both contextualist and non-cognitivist interpretations of claims of free will and responsibility (for contextualist interpretations, see e.g. Unger 2002, pp. 54-58; Hawthorne 2001; Rieber 2006; for a form of non-cognitivism, see Bennett 2008). ${ }^{29}$ Similarly, people have proposed various forms of relativism about disputed

${ }^{29}$ Shafer-Landau is right that disagreements about, say, the possibility of some suitably specified forms of free will seem perfectly objective: "Once we are sure of our terms and concepts, the judgments that affirm or deny the existence of such things are literally either true or false, in as robust a sense as we can imagine." (2006, p. 219) However, once we have reached that level of confidence (and similar confidence that our opponents 
metaphysical claims, and contextualist interpretations of knowledge claims have been widely discussed in epistemology. ${ }^{30}$

If these were special cases, the objectivist could just refer us to other philosophical disagreements. But suspicions that philosophical disagreements are based on verbal confusion and can be cleared up substantially by disambiguation are voiced throughout all fields of philosophy, and are responsible for much of the preoccupation with clarity in the analytic tradition. Such suspicions will be especially acute when disagreements about the extension of a concept seem due to different conceptions of the subject matter.

This is not deny that the parties of various philosophical disagreements that satisfy Central and Fundamental Disagreement might be concerned with a common, objective matter of fact. It is merely to deny that we can take this for granted, and hence to deny that the objective status of these matters can be used to save the straightforward argument.

\section{Third reply: Recourse to non-naturalism}

I have argued that since many moral disagreements seem to depend on fundamentally different conceptions of the referents of moral concepts, objectivists or more specifically absolutists cannot claim to have the most straightforward explanation of 'absolutist' behavior among people engaged in such disagreements. Like relativists and non-cognitivists, they need to provide substantial explanations.

However, normative non-naturalism might make the elusiveness of common satisfaction-conditions for moral concepts seem less troubling (Humer 2005; Moore 1903 ch. 1; Parfit 2005, pp. 330-32; Shafer-Landau 2003). If the satisfaction-conditions of our normative concepts were entirely non-naturalistic, disagreement about their empirical extension and about fundamental empirical

understand the issue in the same way), these disagreements no longer satisfy condition Fundamental Disagreement.

${ }^{30}$ For discussions of relativism about metaphysical claims, see e.g. papers by Eli Hirsch, Terry Horgan and Mark Timmons, Alan Sidelle, and Achille Varzi in Noûs 36, Supplement on Realism and Relativism, 2002. For an overview of discussions of epistemic contextualism, see Rysiew 2009. 
criteria for their application should no more indicate differences in fundamental applicability conditions than disagreements about causes of fluctuations of GDP indicate different concepts of GDP. Moreover, while there seems to be widespread deep disagreement about naturalistic criteria for normative concepts, normative criteria might be more uniform. More people probably agree that morally wrong actions are actions that (knowingly) violate norms that ought to be in force in a society, say, than agree about naturalistic criteria for moral wrongness.

This might suggests that, in spite of apparently deep and widespread moral disagreement, the mechanisms explaining 'absolutist' behavior in the moral domain might be mechanisms that are sensitive to agreement and disagreement in fundamental criteria of application, mechanism that are also operative in various paradigmatically objective domains. If so, the argument from elusive univocality looked threatening only because we confusedly mistook naturalistic criteria of application for such fundamental criteria.

The problem with this reply, apart from worries about non-naturalist properties, is that the nature of moral concepts goes beyond intra-normative inferential relations that we might detect by tracking people's intra-normative criteria of application. On the non-naturalist picture in particular, normative and more narrowly moral concepts also refer to non-natural properties instantiated by certain actions, characters, social arrangements, and so forth. This means that even on non-naturalism, the question would remain why we have come to think that different people employing normative concepts refer to the same non-natural properties. Given widespread disagreement about both the extension of normative concepts and about the non-normative supervenience base of normative properties (i.e. about whether and how normative properties depend upon consequences, motives, forms of respect, etc.), there seems to be strong prima facie evidence that normative concepts are not co-referential. If they nevertheless are and if this somehow explains why engage in 'objectivist' behavior, the non-naturalist objectivist owes us an account of that explanation, as our behavior seems insensitive to apparent disagreements about both fundamental extra-normative criteria and extension of moral concepts. Without such an account, we have no reason to think that the objectivist explanation is better. 


\section{Fourth reply: Intended univocality}

Faced with the problems of both criterial and externalist views of successful concept application, absolutists might want to say that absolutism is not so much something that explains 'absolutist' behavior as it is something that we create by engaging in a common linguistic practice with absolutist intentions. Because our use of concepts involves a commitment to relate to such a common practice they have a common meaning de jure, not just de facto. The idea would be this:

Intended Univocality: 'Absolutist' behavior shows that we intend our moral concepts to have the same non-projective satisfactionconditions or refer to the same properties as others' corresponding moral concepts.

Univocality by Collective Fiat: This multitude of intentions of univocality makes our moral concepts univocal.

If absolutist intentions were meant to account for 'absolutist' behavior only in the moral domain, this would undermine the claim that moral objectivism or absolutism explain such behavior in the same way as it is explained in other domains. However, it seems plausible enough that absolutist behavior in paradigmatically objective domains is at least partly explained by speaker intentions to refer to what others are referring to. Univocality de jure is not unique to moral discourse.

Still, appeal to intended univocality is of little help for the straightforward argument. The first thing to notice is that although it seems plausible that people intend to address the same issue as others who are engaged in moral reasoning, this need not be given an absolutist reading. Relativists and non-cognitivists will deny that 'the same issue' should be understood in terms of non-projective satisfactionconditions or co-reference rather than, say, in terms of practical questions about what to do or feel. The question, then, is what evidence there is for the absolutist interpretation needed for Intended Univocality. Here, the appearance of deep and widespread disagreement makes the absolutist interpretation problematic, as it is unclear why people would continue to refer to what all members of a group are referring when there is considerable prima facie evidence that other members employ different fundamental criteria and track different properties. Judging from 
the argument thus far, this is not how we operate in other domains. This suggests that the absolutist, no less than the relativist or non-cognitivist, needs a special explanation for 'absolutist' behavior in the moral domain.

The second problem is that even if absolutist behavior were straightforwardly explained by intentions of univocality, it is not clear how such intentions would establish absolutism. Univocality intentions will not themselves supply a determinate referent to a sign hitherto lacking one, nor will they make homonyms with different referents co-referential. (If I am using 'fruit' in the everyday sense and you use it in the botanical sense and we both add an intention to talk about the same thing when we use 'fruit', it is not really clear what we would be talking about.)

It might be argued, however, that the latter problem would be solved if univocality intentions involved intentions to resolve differences. In response to difficulties in determining what is required to know the meaning of thin evaluative predicates, Laura and François Schroeter have recently suggested that a speaker competent with the meaning of an evaluative public language term must have a coordinating intention, i.e. an intention 'to use the term in a way that makes best sense of the communal practice' (2009, p. 18). Such an intention commits one to seek a reflective equilibrium between the different parts of the total communal practice with the term, vindicating the most important parts, in particular prototheoretical hunches and substantive ideas about or ways of identifying the referent (2009, 15, 17 e.g.). Simplifying somewhat, the proposal is that insofar as speakers share this intention, they use the term with the same meaning, and insofar as there is a consistent determinate best interpretation of the practice, the term has a referent. $^{31}$

Though intentions to use terms in ways that 'make best sense' of the communal practice might be an important part of participation in public language, it is neither clear how they establish univocality, nor how they would establish

\footnotetext{
${ }^{31}$ Schroeter and Schroeter also require congruence, i.e. that the 'individual speaker's initial understanding of the term must not diverge so radically from that of others in the community as to undermine that coordinating intention' (Schroeter and Schroeter 2009, p.
} 18). 
absolutism. The basic problem is that we have little reason to think that people have a determinate and univocal notion of what it is to make best sense of the practice. Judging from the appearance of widespread and deep moral disagreement, people attach importance to different ways of identifying the referent and different proto-theoretical hunches. Moreover, if they nevertheless have univocal coordinating intuitions, it seems prima facie implausible that they fix a best interpretation determinate enough to yield absolutism. If they nevertheless do, and if they explain 'absolutist' behavior, this needs some special explanation, going well beyond a general appeal to mechanisms operative in other domains.

\section{Concluding remarks}

The basic idea of the argument of this paper is old: in light of what seems like deep and widespread moral disagreement, it is difficult to spell out what we would all be concerned with when thinking that something is, say, immoral. But this difficulty has usually been pressed en route to establishing some substantial non-objectivist position, or en route to undermining cognitivism, realism or moral knowledge, or in arguments to the effect that objectivism is false. ${ }^{32}$ This, I think, is what has led both objectivists and critics to debate whether objectivism is compatible with deep moral disagreement, rather than to ask whether putative reasons for objectivism are compatible with that disagreement, as I have done here. Since the particular version of the argument from disagreement developed here is easily confused with its better-known kin, I will conclude by stressing just what this version is meant to show and not to show.

First, and as I just said, the argument is meant to show that objectivists cannot merely assume that 'objectivist' behavior has the same explanation in the moral domain as it has elsewhere, and that this undermines the straightforward argument. It is not meant to show that objectivism is false. For all I have said here, there might be, say, a convincing transcendental argument for objectivism in the offing.

${ }^{32}$ For a recent exchange, see Brian Leiter's 'Moral Skepticism And Moral Disagreement: Developing An Argument From Nietzsche' with comments from over 20 contributors and replies from Leiter at http://onthehuman.org/2010/03/moral-skepticism-and-moraldisagreement-developing-an-argument-from-nietzsche/ 
Nor is it meant to show that we have no reason to believe in cognitivism. For all I have said, cognitivism might be supported by perfectly good arguments - the Frege-Geach problem for non-cognitivism, say, or the existence of explanations in normative terms - and some arguments for specific relativistic accounts might be perfectly sound.

Second, many central assumptions in arguments for non-cognitivism, relativism or error-theory are unnecessary for this particular argument. For example, the argument does not assume that there is widespread and deep moral disagreement that cannot be plausibly explained away as cognitive error (Mackie 1977, pp. 26-38; cf. Loeb 1998), nor does it assume that objectivism is incompatible with such radical disagreement. It only assumes that many paradigmatic cases of moral disagreement look as if they might be radical. Moreover, the argument does not assume that we normally track moral agreement and disagreement by the practical role of moral concepts in the way that expressivists and some relativist suggest (Wong 1984, p. 73), or that our intuitions of moral agreement or disagreement are determined by whether it is worthwhile to try changing the opponent's mind using rational argument (Tersman 2006, pp. 94, 104). Nor does the argument assume that moral properties have to be natural properties, or that the correctness-conditions of moral judgments must be established in the way that correctness-conditions of scientific or non-normative descriptive judgments are established, or that objectivism presupposes that our veridical moral beliefs tend to be caused by moral facts (cf. Dworkin 1996, pp. 105-8, 12-14). For all I have said, it might very well be that the correctnessconditions of moral judgments are established in Kantian fashion, by way of their constitutive role in practical rationality, or that moral properties are non-natural properties grasped by rational intuition.

What I have argued is that whether non-projective satisfaction-conditions of moral concepts are understood to be determined (a) by our criteria for application of these moral concepts, or (b) by what these concepts have tracked such that this tracking has reinforced their employment, the explanation of 'objectivist' behavior will either be different in the moral domain than in paradigmatically objective domains, or insensitive enough to be equally available for relativists or expressivists. It can neither rely on sameness in any straightforwardly accessible criteria of application precise enough to support absolutism, nor on any 
straightforwardly accessible reinforcement of tracking of the same property or kind. Moreover, I suggest that any plausible view of non-projective satisfactionconditions will be relevantly similar to these two views for the argument to generalize. If this is right, objectivist behavior in the moral domain needs a special explanation even given objectivism. To defend objectivism, then, it would not be enough to argue, on the one hand, that expressivism, relativism, or error-theories and their explanations of 'objectivist' behavior are contrived and implausible and, on the other, that objectivism is compatible with the nature of moral motivation, the extent of moral disagreement, and with reasonable ontological strictures. New evidence for objectivism would also have to be produced.

\section{Acknowledgements}

Various versions of this paper have been benefited from comments from audiences at Stockholm University, Lund University, Uppsala University, the University of Gothenburg, the University of Connecticut, and Oxford University. Special thanks go to Erik Carlson, Thomas Anderberg, Sven Danielsson, the late Jan Österberg, Frans Svensson, Ingmar Persson, Joakim Sandberg, Ragnar Francén Olinder, Torbjörn Tännsjö, John Eriksson, Caj Strandberg, Anna-Karin Andersson, Wlodek Rabinowicz, David Alm, Toni Rønnow-Rasmussen, Johan Brännmark, Jonas Olson, Krister Bykvist, Nicholas Shea, Russ Shaffer-Landau, and several anonymous referees.

\section{References}

(O'Leary-)Hawthorne, John and Huw Price. 1996. How to Stand up for NonCognitivists. Australasian Journal Of Philosophy 74:275-92.

Ayer, Alfred Jules. 1946. Language, Truth and Logic, Gollancz.

Bennett, Jonathan. 2008. Accountability (II). In Free Will and Reactive Attitudes, McKenna, Michael and Russell, Paul (eds.) Ashgate, 47-68.

Björnsson, Gunnar, and Stephen Finlay. 2010. Metaethical Contextualism Defended. Ethics 121: 7-36.

Blackburn, Simon. 1993. Essays in Quasi-Realism, Oxford U. P. Blackburn, Simon. 1998. Ruling Passions, Oxford U. P. 
Boghossian, Paul A. 1990. The Status of Content. The Philosophical Review 99: $157-84$.

Boyd, Richard. 1988. How to be a Moral Realist. In Essays on Moral Realism. Sayre-McCord, Geoffrey (ed) Cornell U. P., 181-228.

Boyd, Richard. 2003. Finite Beings, Finite Good: The Semantics, Metaphysics and Ethics of Naturalist Consequentialism, Part 1. Philosophy and Phenomenological Research 66: 505-53.

Braddon-Mitchell, David. 2004. Masters of Our Meanings. Philosophical Studies, 118: $133-52$.

Brink, David O. 1989. Moral Realism and The Foundations of Ethics, Cambridge U. P.

Brink, David O. 2001. Realism, Naturalism, and Moral Semantics. Social Philosophy and Policy 18: 154-76.

Chalmers, David J., and Frank Jackson. 2001. Conceptual Analysis and Reductive Explanation. The Philosophical Review, 110: 315-60.

Copp, David. 2000. Milk, Honey, and the Good Life on Moral Twin Earth. Synthese 124: 113-37.

Dennett, Daniel. 1984. Elbow Room. The Varieties of Free Will Worth Wanting. The MIT Press / A Bradford Book.

Divers, John, and Alexander Miller. 1994. Why Expressivists about Value Should Not Love Minimalism about Truth. Analysis 54: 12-19.

Dreier, James. 1990. Internalism and Speaker Relativism. Ethics 101: 6-26.

Dreier, James. 2002. Troubling Developments in Metaethics. Nô̂s 36: 152-68.

Dreier, James. 2004. Meta-Ethics and The Problem of Creeping Minimalism. Philosophical Perspectives 18: 23-44.

Dworkin, Ronald. 1996. Objectivity and Truth: You'd Better Believe It. Philosophy and Public Affairs 25: 87-139.

Dummett, Michael. 1959. Truth. Proceedings of the Aristotelian Society, 59: 14162.

Eklund, Matti. Forthcoming, The Multitude View on Logic. In Greg Restall and Gillian Russell (eds.), New Waves in the Philosophy of Logic, Palgrave.

Finlay, Stephen. 2008. The Error in the Error Theory. Australasian Journal of Philosophy 86: 347-69.

Finlay, Stephen. 2009. Oughts and Ends. Philosophical Studies 143: 315-40. 
Firth, Roderick. 1952. Ethical Absolutism and the Ideal Observer. Philosophy and Phenomenological Research 12: 317-45.

Fodor, Jerry. 1990. A Theory of Content and Other Essays, MIT Press.

Fodor, Jerry. 1996. Deconstructing Dennett's Darwin. Mind \& Language 11: 24662.

Francén, Ragnar. 2007. Metaethical Relativism: Against the Single Analysis Assumption, Acta Philosophica Gothoburgensis 24

Gampel, Eric H. 1996. A Defense of the Autonomy of Ethics: Why Value Is Not Like Water. Canadian Journal of Philosophy 26: 191-210.

Gibbard, Allan. 1990. Wise Choices, Apt Feelings, Cambridge MA: Harvard U. P.

Gibbard, Allan. 2003. Thinking How To Live, Harvard U. P.

Goodwin, Geoffrey P., and John M. Darley. 2008. The Psychology of Meta-Ethics: Exploring Objectivism. Cognition, 106: 1339-66.

Harcourt, Edward. 2005. Quasi-Realism and Ethical Appearances. Mind 114: 24975.

Hare, Richard M. 1981. Moral Thinking, Oxford U. P.

Harman, Gilbert. 1998. Responses to Critics. Philosophy and Phenomenological Research 58: 207-13.

Harman, Gilbert and Judith Jarvis Thomson. 1996. Moral Relativism and Moral Objectivity, Blackwell.

Hawthorne, John. 2001. Freedom in Context. Philosophical Studies 104: 63-79

Hirsch, Eli. 2002. Quantifier Variance and Realism. Noûs 36: 51-73.

Holland, Sean. 2001. Dispositional Theories of Value Meet Moral Twin Earth. American Philosophical Quarterly 38: 177-95.

Horgan, Terence, and Mark Timmons. 1991. New-Wave Moral Realism Meets Moral Twin Earth. In Heil, J. (ed.), Rationality, Morality, and Self-Interest. Lanman Md: Rowman and Littlefield, 115-33.

Horgan, Terence, and Mark Timmons. 1992a. Troubles for New Wave Moral Semantics: The Open Question Argument Revived. Philosophical Papers 21: $153-75$.

Horgan, Terence, and Mark Timmons. 1992b. Troubles on Moral Twin Earth: Moral Queerness Revived. Synthese 92: 221-60.

Horgan, Terence, and Mark Timmons. 1996. Troubles for Michael Smith's Metaethical Rationalism. Philosophical Papers 25: 203-31. 
Horgan, Terence, and Mark Timmons. 2000. Copping Out on Moral Twin Earth. Synthese 124: 129-152.

Horgan, Terence, and Mark Timmons. 2002. Conceptual Relativity and Metaphysical Realism. Noûs 36: 74-96.

Horgan, Terence, and Mark Timmons. 2009. Analytical Moral Functionalism Meets Moral Twin Earth. In Ian Ravenscroft (ed.), Minds, Ethics, and Conditionals: Themes from the Philosophy of Frank Jackson. Oxford U. P.

Huemer, Michael. 2005. Ethical Intuitionism, Palgrave Macmillan.

Jackson, Frank, and Philip Pettit. 1995. Moral Functionalism and Moral Motivation. The Philosophical Quarterly, 45: 20-40.

Joyce, Richard. 2002. The Myth of Morality, Cambridge U. P.

Korsgaard, Christine. 1996. The Sources of Normativity, Cambridge U. P.

Korsgaard, Christine. 2009. Self-Constitution, Oxford U. P.

Lear, Jonathan. 1983. Ethics, Mathematics and Relativism. Mind, 92: 38-60.

Leiter, Brian. 2010. Moral Skepticism And Moral Disagreement: Developing An Argument From Nietzsche. http://onthehuman.org/2010/03/moralskepticism-and-moral-disagreement-developing-an-argument-fromnietzsche/

Lenman, James. 2003. Disciplined Syntacticism and Moral Expressivism. Philosophy and Phenomenological Research 66: 32-57.

Lewis, David. 1997. Naming the colours. Australasian Journal Of Philosophy, 75: 325-42.

Lillehammer, Hallvard. 2007. Companions in Guilt, Pallgrave Macmillian

Loeb, Don. 1998. Moral Realism and the Argument from Disagreement. Philosophical Studies 90: 281-303.

Loeb, Don. 2007. The Argument from Moral Experience. Ethical Theory And Moral Practice 10: 469-84.

MacFarlane, John. 2007. Relativism and disagreement. Philosophical Studies 132: $17-31$.

Mackie, John L. 1977. Ethics: Inventing Right and Wrong, Penguin

McDowell, John. 1983. Aesthetic Value, Objectivity of World. In Pleasure, Preference and Value: Studies in Philosophical Aesthetics, vol. Schaper, E. V. A. (ed) Cambridge University Press: 1-16. 
McDowell, John. 1985. Values and Secondary Qualities. In Morality and Objectivity, vol. Honderich, T. E. D. (ed) Routledge and K Paul, 110-29.

McNaughton, David. 1988. Moral Vision: an Introduction to Ethics, Blackwell.

Merli, David. 2008. Expressivism and the Limits of Moral Disagreement. Journal of Ethics 12: 25-55.

Merli, David. 2002. Return to Moral Twin Earth. Canadian Journal of Philosophy 32: $207-40$.

Millikan, Ruth Garrett. 2000. On Clear and Confused Ideas: An Essay about Substance Concepts, Cambridge U. P.

Millikan, Ruth Garrett. 2010. On Knowing the Meaning; With a Coda on Swampman. Mind 119: 43-81

Moore, George Edward. 1903. Principia Ethica, Cambridge U. P.

Nagel, Thomas. 1997. The Last Word, Oxford U. P.

Nichols, Shaun. 2004. Sentimental Rules, Oxford U. P.

Papineau, David. 1998. Teleosemantics and Indeterminacy. Australasian Journal Of Philosophy 74: 1-14.

Parfit, Derek. 2005. Normativity. In Oxford Studies in Metaethics, vol. 1, ShaferLandau, Russ (ed): 325-80.

Parfit, Derek 2011. On What Matters. Oxford U. P.

Pettit, Philip. 1998. Practical Belief and Philosophical Theory. Australasian Journal Of Philosophy 76: 15-33.

Pettit, Philip 1999. A Theory of Normal and Ideal Conditions. Philosophical Studies 96: 21-44.

Price, Carolyn. 1998. Determinate Functions. Nô̂s 32: 54-75.

Putnam, Hilary. 1975. The Meaning of 'Meaning'. In Mind, Language and Reality, vol. 2, Cambridge U. P., 215-71.

Rieber, Steven. 2006. Free Will and Contextualism. Philosophical Studies 129: $223-52$

Rosen, Gideon. 1998. Blackburn's Essays in Quasi-Realism. Noûs 32: 386-405.

Ryan, James A. 2003. Moral Relativism and the Argument from Disagreement. Journal of Social Philosophy 34: 377-86.

Rysiew, Patrick. 2009. Epistemic Contextualism. In The Stanford Encyclopedia of Philosophy (Spring 2009 Edition), Edward N. Zalta (ed.), URL = 
$<$ http://plato.stanford.edu/archives/spr2009/entries/contextualismepistemology/>

Sarkissian, Hagop, John Park, David Tien, Jen Cole Wright, and Joshua Knobe. 2011. Folk Moral Relativism. Mind \& Language 26: 482-505

Sayre-McCord, Geoffrey. 1991. Being a Realist About Relativism (in Ethics). Philosophical Studies 61: 155-76.

Sayre-McCord, Geoffrey. 1997. 'Good' On Twin Earth. Philosophical Issues 8: 267-92.

Sayre-McCord, Geoffrey. 2006. Moral Realism. In The Oxford Handbook of Ethical Theory. Copp, David (ed) Oxford: Oxford U. P., 39-62.

Schroeder, Mark. 2008a. Being For, Oxford U. P.

Schroeder, Mark. 2008b. How Expressivists Can and Should Solve Their Problem with Negation. Noûs 42: 573-99.

Schroeter, Laura, and François Schroeter. 2009. A Third Way in Metaethics. Nô̂s, 43: $1-30$.

Shafer-Landau, Russ. 1994. Ethical Disagreement, Ethical Objectivism and Moral Indeterminacy. Philosophy and Phenomenological Research 54: 331-44.

Shafer-Landau, Russ. 2003. Moral Realism: A Defence, Oxford U. P.

Shafer-Landau, Russ. 2006. Ethics as Philosophy: A Defense of Ethical Nonnaturalism. In Metaethics after Moore, vol. Horgan, Terry and Timmons, Mark (eds) Oxford U. P., 209-32.

Sidelle, Alan. 2002. Is There a True Metaphysics of Material Objects? Nô̂s 36: $118-45$.

Sinclair, Neil. 2006. The Moral Belief Problem. Ratio (new series) 19: 249-60.

Smith, Michael. 1994. The Moral Problem, Basil Blackwell.

Stevenson, Charles L. 1937. The Emotive Meaning of Ethical Terms. Mind 46: 1431.

Stoljar, Daniel. 1993. Emotivism and truth conditions. Philosophical Studies 70: 81-101.

Street, Sharon. 2006. A Darwinian Dilemma for Realist Theories of Value. Philosophical Studies, 127: 109-66.

Streiffer, Robert. 2003. Moral Relativism and Reasons for Action, Routledge.

Sturgeon, Nicholas. 1994. Moral Disagreement and Moral Relativism. Social Philosophy and Policy 11: 80-115. 
Tersman, Folke. 2006. Moral Disagreement, Cambridge U. P.

Timmons, Mark. 1999. Morality without Foundations, Oxford U. P.

Unger, Peter. 2002. Philosophical Relativity, Oxford U. P.

Varzi, Achille C. 2002. On Logical Relativity. Noûs 36: 197-219.

Wallace, R. Jay. 1994. Responsibility and the Moral Sentiments, Harvard U. P.

Wedgwood, Ralph. 2001. Conceptual Role Semantics for Moral Terms. The Philosophical Review 110: 1-30.

Wong, David. 1984. Moral Relativity, University of California Press.

Wright, Crispin. 1985. Review of Spreading the Word: Groundings in the Philosophy of Language. Mind 94: 310-19.

Yasenchuk, Ken. 1997. Moral Realism and the Burden of Argument. The Southern Journal of Philosophy 35: 247-64. 